\title{
Softening by Severe Plastic Deformation and Hardening by Annealing of Aluminum-Zinc Alloy: Significance of Elemental and Spinodal Decompositions
}

\author{
Ali Alhamidi ${ }^{1,2, *}$, Kaveh Edalati ${ }^{1,2}$, Zenji Horita ${ }^{1,2}$, Shoichi Hirosawa ${ }^{3}$, \\ Kenji Matsuda ${ }^{4}$ and Daisuke Terada ${ }^{5}$ \\ ${ }^{1}$ Department of Materials Science and Engineering, Faculty of Engineering, Kyushu \\ University, Fukuoka 819-0395, Japan \\ ${ }^{2}$ WPI, International Institute for Carbon-Neutral Energy Research (WPI-I2CNER), Kyushu \\ University, Fukuoka 819-0395, Japan \\ ${ }^{3}$ Department of Mechanical Engineering and Materials Science, Yokohama National \\ University, Yokohama 240-8501, Japan \\ ${ }^{4}$ Graduate School of Science and Engineering for Research, University of Toyama, Toyama \\ 930-8555, Japan \\ ${ }^{5}$ Department Materials Science and Engineering, Faculty of Engineering, Kyoto University, \\ Kyoto 606-8501, Japan
}

An Al - 30 mol.\% Zn supersaturated solid solution alloy was severely deformed using highpressure torsion (HPT) at $300 \mathrm{~K}$ and subsequently annealed at 373-673 $\mathrm{K}$. The hardness and tensile strength significantly decreased and the tensile ductility increased with straining by HPT and reached a steady-state level at large imposed strains. Despite this softening behavior, the lattice strain was increased, Zn-rich particles were precipitated and the initial coarse grains were refined significantly to a size of $\sim 190 \mathrm{~nm}$ while being accompanied by decomposition to Al- and Zn-rich phases because of rapid atomic diffusion. The subsequent annealing led to a hardening, but microstructural observations showed that decrease in the lattice strain, increase in the grain size and reduction in the fraction of precipitates occurred by annealing. It was shown that the unusual softening/hardening behavior of the Al-Zn alloy was mainly due to the contribution of spinodal decomposition. The formation of nano-sized lamellae by spinodal decomposition resulted in increase in hardness after solution treatment and after post-HPT annealing, while this lamellar structure was destroyed by HPT which resulted in softening. The softening was less significant when the hardness was evaluated at low homologous temperatures.

Keywords: Severe plastic deformation (SPD); High-pressure torsion (HPT); Ultrafine-grained (UFG) materials; Phase transformation; Solution hardening.

*Corresponding author, TEL/FAX: +81-92-802-2992; e-mail: ali@zaiko6.zaiko.kyushu-u.ac.jp 


\section{Introduction}

Severe plastic deformation (SPD) methods such as Equal-Channel Angular Pressing (ECAP) [1-6], Accumulative Roll-Bending (ARB) [7,8] and High-Pressure Torsion (HPT) [918] are well-known processing procedures in which high densities of lattice defects and ultrafine grains (UFG) are achieved in metallic materials by imparting large strains. Among the different techniques for the SPD process introduced so far (see reviews in Refs. [18-21]), HPT is especially effective to introduce large plastic strains for grain refinement up to a steady state [9-18] where the hardness and microstructure remain unchanged with straining. The method is also capable of controlling the solid-state phase transformations in metallic materials [22-25] and even in non-metallic materials such as $\mathrm{Si}$ [26], $\mathrm{C}$ [27] and $\mathrm{ZrO}_{2}$ [28].

In general, most metallic materials show hardening due to grain refinement through the Hall-Petch relationship. However, recent papers reported three different types of hardnessstrain behaviors after HPT processing. First, in metals with high melting temperatures such as Fe and $\mathrm{Ti}$, a steady state is reached directly following the initial hardening with straining $[10,11,13,29]$. Second, in metals with moderate melting temperatures such as $\mathrm{Al}$ and $\mathrm{Mg}$, the hardness initially increases with increasing strain and, after reaching a maximum, decreases to a steady-state level [30-34]. This behavior was also detected in several metals and alloys when processed at high homologous temperatures [29,35-37]. Third, in metals with low melting temperatures such as $\mathrm{Zn}, \mathrm{Pb}, \mathrm{Sn}$ and $\mathrm{In}$, the hardness slightly decreases with an increase in strain at an early stage of straining and enters into a steady state at large strains $[29,38]$. This strain softening behavior was also reported in nanograined $\mathrm{Ni}[12,13]$ as we all as in several alloys such as a Pb-Sn eutectic alloy [39], a $\mathrm{Zn}-\mathrm{Al}-\mathrm{Cu}$ alloy [40], $\mathrm{Zn}-\mathrm{Al}$ monotectoid alloys [39-42] and Al-Zn alloys [43-51].

Although several publications reported a significant decrease in hardness up to $130 \mathrm{Hv}$ in the Al-Zn alloys after SPD processing using HPT method [43-51], the mechanism for this unusual softening is not clearly understood. The softening, which was also reported during 
cold rolling [52], ball milling [53] and ECAP [54,55], was mainly attributed to elemental decomposition and reduction of the solid solution hardening. However, as shown in Appendix 1, the theoretical models such as the Fleischer' model [56] and the Labusch's model [57] predict a small solid solution hardening in the Al-Zn alloys because of weak elastic and modulus interactions between solute atoms and matrix.

In this study, we thus investigate the softening mechanism in an $\mathrm{Al}-30 \mathrm{~mol} \% \mathrm{Zn}$ ( $\sim 51$ wt. $\% \mathrm{Zn})$ alloy by HPT and show the critical importance of spinodal decomposition and homologous temperature on this softening. The evolution of microstructure and mechanical properties along with HPT processing as well as after subsequent annealing are investigated.

\section{Experimental procedures}

Pure Al (99.99\%) was alloyed with 30 mol.\% Zn (99.99\%) by melting in air at $1123 \mathrm{~K}$ in an alumina crucible. According to the Al-Zn phase diagram, the alloy exhibits a liquidus temperature (Liq. $\rightarrow \alpha+$ Liq.) at $830 \mathrm{~K}$, solidus temperature $(\alpha+$ Liq. $\rightarrow \alpha)$ at $750 \mathrm{~K}$, phase separation at $610 \mathrm{~K}\left(\alpha \rightarrow \alpha_{1}+\alpha_{2}\right)$ and monotectoid transformation $\left(\alpha_{2} \rightarrow \alpha_{1}+\beta\right)$ at $550 \mathrm{~K}(\alpha$ : AlZn solid solution with the fcc structure, $\alpha_{1}, \alpha_{2}$ : Al-rich and Zn-rich phases with the fcc structure, respectively, $\beta$ : Zn-rich phase with the hcp structure) [58]. The alloy was cast into a mold with dimensions of $30 \times 20 \times 80 \mathrm{~mm}^{3}$. The ingot was homogenized at $703 \mathrm{~K}$ for $24 \mathrm{~h}$ and cooled in air. The homogenized ingot was sliced into sheets with $8 \mathrm{~mm}$ thickness using a wire-cutting electrical discharge machine. The sheets with $8 \mathrm{~mm}$ thickness were rolled at room temperature and their thickness was reduced to $1.2 \mathrm{~mm}$.

The cold-rolled sheets were subsequently solution-treated at $673 \mathrm{~K}$ for $1 \mathrm{~h}$ and quenched rapidly in ice water to give an initial grain size of $\sim 130 \mu \mathrm{m}$ (as in Fig. 1(a)) with hardness of $\sim 182 \mathrm{Hv}$. It should be noted that this hardness is unusually high because a spinodal decomposition occurred during the rapid cooling as will be mentioned later. The sheets after the solution-treatment (hereafter, called S.T.) were cut to discs with $10 \mathrm{~mm}$ 
diameter and $1.2 \mathrm{~mm}$ thickness and HPT was carried out on the discs at room temperature $(\sim 300 \mathrm{~K})$ under a pressure of $P=6 \mathrm{GPa}$ for $N=1,3,10$ and 25 revolutions using the facilities described in details earlier [11,59]. The HPT-processed samples after $N=25$ revolutions were annealed at $373,423,473,523,593,623,643,673 \mathrm{~K}$ for $24 \mathrm{~h}$ and cooled down rapidly in air. Annealing was also conducted on the HPT-processed samples after $N=25$ revolutions at 373 $\mathrm{K}$ for different periods of time such as $0.5,1,5$ and $24 \mathrm{~h}$. All samples were kept in a freezer at a temperature of $243 \mathrm{~K}$ before processing as well as before experimental analyses.

As reference materials, discs of pure $\mathrm{Al}(99.99 \%)$ and $\mathrm{Zn}$ (99.99) with 10mm diameter and $0.8 \mathrm{~mm}$ thickness were also used in this study. The discs of $\mathrm{Al}$ and $\mathrm{Zn}$ were annealed for 1 hour at $773 \mathrm{~K}$ and $523 \mathrm{~K}$, respectively, under an argon atmosphere to give a grain size of $\sim 1$ $\mathrm{mm}$ for $\mathrm{Al}$ and $\sim 390 \mu \mathrm{m}$ for $\mathrm{Zn}$. HPT was carried out on the annealed discs at room temperature under a pressure of $P=6 \mathrm{GPa}$ for $N=5$ and 15 revolutions.

Following the HPT processing and annealing, the Vickers microhardness was measured at $300 \mathrm{~K}$ with an applied load of $200 \mathrm{~g}$ for $15 \mathrm{~s}$ along 12 radial directions of the discs with an incremental step of $0.5 \mathrm{~mm}$. The Vickers micohardness measurements were also carried out on several samples at cryogenic temperatures $(\sim 90 \mathrm{~K})$ in liquid nitrogen.

Crystallographic structures were analyzed by X-ray diffraction (XRD) analysis using the $\mathrm{Cu} \mathrm{K} \alpha$ radiation in a scanning step of $0.01-0.02^{\circ}$ and a scanning speed of $0.5-1 \% \mathrm{~min}$. The XRD patterns are obtained from a $\sim 3 \mathrm{~mm}$ diameter region at the edge of the discs. $\mathrm{LaB}_{6}$ standard powders were used concurrently with the samples during XRD analysis for offsetting any possible peak shifts between measurements.

For transmission electron microscopy (TEM) and scanning transmission electron microscopy (STEM), thin samples were prepared at $3.5 \mathrm{~mm}$ away from the center of the HPTprocessed discs using either a focused ion beam system or a twin-jet electro-chemical polisher in a solution of $33 \% \mathrm{HNO}_{3}$ and $67 \% \mathrm{CH}_{3} \mathrm{OOH}$ at $263 \mathrm{~K}$ under a voltage of $18 \mathrm{~V}$. TEM and STEM were performed at 200 and $300 \mathrm{kV}$, respectively, for microstructure observation, 
selected-area electron diffraction (SAED) analysis and energy dispersive X-ray spectrometry (EDS).

For examination of tensile properties, miniature tensile specimens having gauge dimensions of $1.5 \mathrm{~mm}$ length, $0.5-0.7 \mathrm{~mm}$ width and $0.5 \mathrm{~mm}$ thickness were cut from the discs at the position $2 \mathrm{~mm}$ away from the disc center using a wire-cutting electrical discharge machine. Each tensile specimen was mounted horizontally on grips and pulled to failure using a tensile testing machine with an initial strain rate of $2 \times 10^{-3} \mathrm{~s}^{-1}$.

\section{Results}

Figure 1(b) shows a TEM bright-field image and corresponding SAED pattern of a sample after solution treatment. It is apparent that the initial coarse microstructure consists of very fine lamellae with a width of $\sim 35 \mathrm{~nm}$. The SAED pattern corresponds to the $\alpha$ phase with the fcc structure, confirms that the structure consists of a single grain and a single crystallographic structure. Since no evidence for the Zn-rich $\beta$ phase was found using SAED and XRD analysis (see Fig. 4 for XRD profiles of solution-treated sample), the lamellar structure corresponds to neither the eutectic structure nor the monotectoid structure, but corresponds to the spinodal decomposition. It should be noted that although the sample was quenched in ice water quickly (in a few seconds) after solution treatment, the occurrence of spinodal decomposition could not be avoided. The occurrence of spinodal decomposition should be the main reason for unusually high hardness of the solution-treated sample $(\sim 182$ Hv) when compared to the predictions of solution hardening models, as shown in Fig. A1. The occurrence of spinodal decomposition in the Al-Zn alloys was investigated in several papers [60-63].

Figure 2 shows the hardness variation with (a) the distance from the disc center and (b) the shear strain for the samples processed by HPT through revolutions from 1 to 25. Here, the shear strain was calculated as [20] 


$$
\gamma=\frac{2 \pi r N}{h}
$$

where $r$ is the distance from the disc center, $N$ is the number of revolutions and $h$ is the disc thickness. The microhardness decreases with an increasing number of revolutions and an increasing the distance from the center. The hardness decreases to the level as small as $28 \mathrm{Hv}$ and enters into a steady state at shear strains larger than 200. Figure 2(b) shows clearly that the hardness variation is represented reasonably by a unique function of the shear strain except for a few data points after $N=25$, which deviate from the fitted line. It should be noted that all hardness values after the HPT processing are smaller than the level of $182 \mathrm{Hv}$ attained by the solution treatment. Moreover, the steady-state hardness is even lower than that for the HPT-processed pure Al (32 Hv) with an average grain size of $\sim 1.3 \mu \mathrm{m}$ and that for the HPTprocessed pure $\mathrm{Zn}(34 \mathrm{Hv})$ with an average grain size of $\sim 20 \mu \mathrm{m}$. This unusual hardnessstrain behavior is basically similar to the earlier observations of pure metals with low melting temperatures such as In [29], $\mathrm{Sn}[29], \mathrm{Pb}[29]$ and $\mathrm{Zn}$ [38] and a few $\mathrm{Pb}-\mathrm{Sn}$ [39], $\mathrm{Zn}-\mathrm{Al}-\mathrm{Cu}$ [40], Zn-Al [39-42] and Al-Zn [43-51] alloys.

Figure 3 shows microhardness plotted against (a) annealing temperature for the samples processed through $N=25$ and subsequently annealed for $24 \mathrm{~h}$ and (b) annealing time for the samples processed through $N=25$ and subsequently annealed at $373 \mathrm{~K}$. The results show that the hardness tends to increase unusually with increasing the annealing temperature and annealing time.

XRD profiles are shown in Fig. 4 for (a) the samples after solution treatment and after HPT processing for different revolutions, and (b) the samples after HPT processing for $N=25$ and after subsequent annealing at different temperatures for $24 \mathrm{~h}$. The following several important points arise. 
(i) No peak for $\mathrm{Zn}$ phase is detected in the solution-treated sample. This clearly shows that a supersaturated state has been attained, where $\mathrm{Zn}$ atoms are fully dissolved in the Al matrix.

(ii) The peaks for Zn phase appear after HPT processing for $N=1$ and the intensity of the $\mathrm{Zn}$ peaks increases with the increasing number of revolutions. This indicates that the elemental decomposition occurs by HPT processing and the fraction of $\mathrm{Zn}$ increases with the increasing number of revolutions (i.e., increasing shear strain). Elemental decomposition by HPT processing was reported earlier in supersaturated Al-Zn, Al$\mathrm{Mg}, \mathrm{Al}-\mathrm{Zn}-\mathrm{Mg}$ and $\mathrm{Co}-\mathrm{Cu}$ alloys [22,43-51].

(iii) The peaks are broadened after processing by HPT and the full width at half maximum (FWHM) increases with increasing the number of revolutions. The peak broadening is an important evidence that the lattice strain is accumulated, grains are fragmented to increase the grain boundary fraction and dislocations are generated in the samples during the HPT processing.

(iv) The $\mathrm{Zn}$ phase remains after the post-HPT annealing at $373-523 \mathrm{~K}$ which is consistent with the equilibrium phase diagram of the Al-Zn system where the $\alpha_{1}$ phase and the $\beta$ phase coexist at temperatures below $550 \mathrm{~K}$ [58]. The fraction of the $\mathrm{Zn}$ phase significantly decreases with annealing at $593 \mathrm{~K}$ (region of $\alpha_{1}+\alpha_{2}$ phases) and the $\mathrm{Zn}$ phase totally disappears with annealing at 623-673 K (region of single $\alpha$ phase).

(v) The FWHM decreases with annealing, indicating that a thermal recovery and/or recrystallization occur during the annealing and the density of dislocations and the fraction of grain boundaries decrease. It is noted that the annealing temperature of 373-673 K corresponds to $0.44-0.80 T_{\mathrm{m}}$ where $T_{m}=830 \mathrm{~K}$ is the melting point of the alloy. It was shown earlier that static recovery and recrystallization occur intensely in the HPT-processed metals at homologous temperatures higher than $0.3 T_{\mathrm{m}}[29,35]$. 
(vi) Peak positions of $\mathrm{Al}$ are shifted to lower angles in the sample processed by HPT for $N$ $=25$ with respect to the peak positions after solution treatment. It is evident that the lattice parameter of $\mathrm{Al}$ must be increased because of depletion of $\mathrm{Zn}$ from the $\mathrm{Al}$ matrix. However, peak positions of $\mathrm{Al}$ are shifted again to higher angles in the samples annealed after HPT, indicating that the dissolution of $\mathrm{Zn}$ in the Al matrix should have occurred after annealing.

Figure 5 shows TEM micrographs and corresponding SAED patterns of the samples after HPT processing for $(\mathrm{a}, \mathrm{b}) N=1$ and $(\mathrm{c}, \mathrm{d}) N=10$, where (a-c) are bright-field images and (d) is a dark-field image of (c) taken with the diffracted beams indicated by an arrow in the SAED pattern. Here, (a) and (b) correspond to an early stage of straining, $\gamma=27$, where the hardness decreases with straining, and (c) and (d) correspond to the steady state of straining, $\gamma=270$, where the hardness remains unchanged with straining. It is apparent from Fig. 5(a) that the initial coarse grains with nano-sized lamellar structure are mainly transformed to equiaxed grains with the submicrometer sizes after $N=1$. While the lamellar structure is still locally visible after $N=1$, as in (b), the lamellae totally disappear at the steady sate in Figs. 5(c) and (d). In Figs. 5(c) and (d), the grains become smaller to an average size of $\sim 190 \mathrm{~nm}$ and the grain boundaries increase their misorientation angles because the diffractions spots are now more scattered around rings. The number of diffracted beams in the SAED patterns, obtained using an aperture size of $1.6 \mu \mathrm{m}$, increases with the increase in the revolutions from 1 to 10 , indicating that the grains are smaller after $N=10$.

Figure 6 shows (a, d) STEM bright-field images and the corresponding EDS mappings of (b, e) Al and (c, f) Zn for the sample after HPT processing for $N=25$. This microstructural characterization indicates several important points. First, the distribution of $\mathrm{Al}$ and $\mathrm{Zn}$ elements is heterogeneous after HPT processing and the elemental decomposition occurs in accordance with the XRD analyses. Second, the grain sizes are well below $500 \mathrm{~nm}$ in consistency with the TEM dark-field images. Third, the grain boundaries are smooth and 
well-defined after HPT processing. Fourth, spinodal decomposition with lamellar structure cannot be detected. Fifth, many nano-sized Zn precipitates (dark particles in bright grains) form homogenously in the Al-rich grains after HPT processing. The formation of precipitates in the Al-Zn alloys was also reported during low-temperature annealing or aging [64-67].

Figure 7 shows TEM bright-field images and the corresponding SAED patterns for samples annealed at (a) $373 \mathrm{~K}\left(\alpha_{1}+\beta\right.$ region), (b) $593 \mathrm{~K}\left(\alpha_{1}+\alpha_{2}\right.$ region) and (c) $673 \mathrm{~K}$ ( $\alpha$ region) after HPT processing for $N=25$. This microstructural characterization indicates that the size of equiaxed grains increases after annealing at $373 \mathrm{~K}$ and the grain growth becomes more significant with increasing the annealing temperature. The lamellar structure resulting from spinodal decomposition appears locally after annealing, as indicated by arrows, while its fraction increases with increasing the annealing temperature. The lamellar structure occupies the whole coarse-grained microstructure after annealing at $673 \mathrm{~K}$ which is similar to the features of the solution-treated sample. These characteristic features appear to be typical structures after spinodal decomposition [60-63].

Microstructure of the sample annealed at $373 \mathrm{~K}$ for $24 \mathrm{~h}$ was further examined with STEM to examine the effect of annealing on the $\mathrm{Zn}$ precipitates and on the reoccurrence of spinodal decomposition. Figure 8 shows (a, c, e) STEM bright-field images taken from different parts and the corresponding EDS mappings of (b, d) Al and (f) $\mathrm{Zn}$ for the sample after HPT processing for $N=25$ and subsequent annealing at $373 \mathrm{~K}$ for $24 \mathrm{~h}$. This microstructural characterization indicates several important points. First, the distribution of elements is not homogenous after post-HPT annealing because of elemental decomposition. Second, a bimodal microstructure develops after annealing which includes ultrafine equiaxed grains as in (a) and (b) and spinodal decomposition structure containing Al-rich and Al-poor lamellae as in (c) and (d). Third, the average grain size increases from $\sim 190 \mathrm{~nm}$ after HPT to $\sim 530 \mathrm{~nm}$ after the annealing process. Fourth, the grain boundaries which were smooth and well-defined after HPT processing become even smoother after post-HPT annealing as shown 
in (a). Fifth, although the fraction of Zn precipitates significantly decreases after post-HPT annealing, some precipitates are locally visible in the equiaxed grains, as indicated by arrows in (e) and (f).

Figure 9 shows (a) a high-resolution TEM image including the corresponding diffractograms obtained by Fast Fourier Transform (FFT) analyses from square regions marked (b) A and (c) B in (a) for the sample after HPT processing and subsequent annealing at $373 \mathrm{~K}$ for $24 \mathrm{~h}$. The analyses show that region $\mathbf{A}$ corresponds to an $\mathrm{Al}$ phase of the matrix and $\mathbf{B}$ to a $\mathrm{Zn}$ phase of a precipitate. This observation confirms that the precipitates detected after HPT and after post-HPT annealing, as in Figs. 6 and 8, are Zn particles.

The stress-strain curves are depicted in Fig. 10 from tensile testing conducted at room temperature with an initial strain rate of $2 \times 10^{-3} \mathrm{~s}^{-1}$ for the samples processed by HPT through $N=1,3,10$ and 25 and for the sample processed after $N=25$ and subsequently annealed at $373 \mathrm{~K}$ for $24 \mathrm{~h}$, including the solution-treated sample. The tensile strength decreases and the uniform elongation as well as the total elongation to failure increases with an increase in the number of revolutions or an increase in the shear strain imposed by the HPT processing. Both tensile strength and the elongation to failure improve after the annealing. The super-ductility reported in an Al-Zn alloy with $30 \mathrm{wt} . \% \mathrm{Zn}(15 \mathrm{~mol} . \%)$ after HPT processing [46] is not achieved in this study even after annealing, perhaps because of the difference in the composition. It should be noted that for the solution-treated and HPT-processed samples, the tensile strength is expressed by the hardness through the relations as UTS $=0.37 \mathrm{HV}$ and UTS $=0.51 \mathrm{HV}$, respectively, where the factor of 0.51 is larger than the factor, $\sim 1 / 3$, accepted generally for the conversion for many isotropic metals. Similar inconsistencies can also be found in other anisotropic materials such as $\mathrm{Co}$ [27], $\mathrm{Zn}$ [38] and semi-conductors [68]. The increase in UTS/HV to 0.51 in the Al-Zn alloy after the HPT processing should be due to the formation of anisotropic $\mathrm{Zn}$ phase which may produce a difference in dislocation activity between uniaxial tensile test and multiaxial hardness measurement. 


\section{Discussion}

Two issues need to be discussed more in details: (i) softening by HPT and hardening by annealing and (ii) elemental decomposition during HPT and spinodal decomposition during annealing. The softening of pure metals at large strains may be attributed to easy recovery of dislocations [31], easy recrystallization [35] and/or grain growth [12]. However, the same mechanisms cannot be applied for the softening at large strains in the present Al-Zn alloy because the hardness decreases despite the fact that the grain size becomes small and the peak broadening in the XRD profiles occurs. It is apparent that the former observation is against the Hall-Petch relationship and the latter against the hardening by stain accumulation due to dislocations. Moreover, the decrease in hardness after HPT processing is accompanied by the precipitation of fine particles, but instead the hardness increases despite the fact that most of the precipitates disappear by the post-HPT annealing. This observation is clearly against the principle of precipitation hardening.

Huang et al. [69] suggested that the effect of dislocations on the hardness can be totally different in nanograined pure metals when compared to coarse-grained metals. They suggested that, when no dislocations exist within nanograins, extra stress is required to create mobile dislocations for deformation and the metal shows dislocation source-limited hardening. However, there are many sources for dislocation generations in the current Al-Zn alloy such as grain boundaries, interphase boundaries and precipitates. The strain softening observed in this study should be attributed mainly to the transformation from the nano-sized lamellar structure to the submicrometer-sized equiaxed grain structure and partly to the low homologous temperature of the system. It should be noted that he softening is hardly

exceeded by the solution hardening through elemental decomposition because the effect of solution hardening is rather weak in this alloy as described in Appendix 1. 
The occurrence of spinodal decomposition after solution treatment and rapid quenching suggests that the high hardness reported in Al-Zn alloys in many publications [4355,60-67] should be due to the spinodal decomposition rather than unusual solution hardening effect. All microstructural observations in this study show that the destruction of the fine structure due to spinodal decomposition and the formation of equiaxed grains is the main reason for the softening after HPT processing. After subsequent annealing, on the one hand dissolution of precipitates occurs in some regions to reach the equiblirium condition and on the other hand spinodal decomposition occurs in other regions with solid solution highly supersaturated. If the supersaturation is not so high, spinodal decomposition does not occur but a nucleation and growth proceeds because of thermo-dynamical reasons [70].

The selected Al-Zn alloy has a low melting temperature as $\sim 830 \mathrm{~K}$ and thus room temperature corresponds to a homologous temperature as $T / T_{m}=0.36$. Moreover, the Al-Zn alloy decomposes to $\mathrm{Al}$ and $\mathrm{Zn}$ after HPT which both metals have low melting temperatures as $933 \mathrm{~K}$ and $693 \mathrm{~K}$, respectively. Therefore, room temperature corresponds to homologous temperatures as 0.32 for $\mathrm{Al}$ and 0.43 for $\mathrm{Zn}$. These homologous temperatures are high for materials with high densities of lattice defects as after HPT processing [29]. It was shown earlier that at high homologous temperatures, the hardness after processing by HPT decreases below the hardness level of the coarse-grained samples despite a decrease in the grain size through HPT processing $[29,38]$. It should be noted that the Hall-Petch relation is invalid at high homologous temperatures because of the effect of grain boundaries which may act as dislocation sinks, cause grain boundary sliding and/or facilitate the flow of vacancies [71]. An example is found in an application of HPT to an $\mathrm{Al}-3 \% \mathrm{Mg}-0.25 \% \mathrm{Sc}$ alloy where an ultrafine-grained structure was attained so that the HPT-processed sample exhibited higher hardness than the coarse-grained sample when measured at room temperature but smaller when tested at higher homologous temperatures [72]. 
In order to show the significance of homologous temperature on the hardening/softening behavior, Table 1 gives the average grain size, the hardness at $300 \mathrm{~K}$ and the hardness at $90 \mathrm{~K}$ for pure $\mathrm{Al}$ and pure $\mathrm{Zn}$ after annealing and HPT processing as well as for the Al-Zn alloy after solution treatment and HPT processing. Table 1 indicates several important points regarding the importance of homologous temperature.

(i) When hardness is measured at $300 \mathrm{~K}$, the fine-grained HPT-processed $\mathrm{Zn}(\sim 20 \mu \mathrm{m}$ grain size $)$ has a hardness lower than the coarse-grained annealed $\mathrm{Zn}(\sim 390 \mu \mathrm{m}$ grain size). However, when hardness is measured at $90 \mathrm{~K}$, the fine-grained $\mathrm{Zn}$ has a hardness higher than the hardness of coarse-grained sample.

(ii) The difference between the hardness of fine-grained HPT-processed $\mathrm{Al}(\sim 1.3 \mu \mathrm{m}$ grain size) and the coarse-grained annealed $\mathrm{Al}(\sim 1000 \mu \mathrm{m}$ grain size $)$ is only $10 \mathrm{Hv}$ when hardness is measured at $300 \mathrm{~K}$, but the difference is as high as $48 \mathrm{Hv}$ when the hardness is measured at $90 \mathrm{~K}$.

(iii) The difference between the hardness of ultrafine-grained HPT-processed Al-Zn alloy $(\sim 190 \mathrm{~nm}$ grain size) and coarse-grained solution-treated Al-Zn alloy $(\sim 130 \mu \mathrm{m}$ grain size) significantly decreases when the hardness is measured at $90 \mathrm{~K}$.

(iv) When hardness is measured at $300 \mathrm{~K}$, the ultrafine-grained HPT-processed Al-Zn alloy ( $\sim 190 \mathrm{~nm}$ grain size) has a hardness lower than the HPT-processed $\mathrm{Al}(\sim 1.3 \mu \mathrm{m}$ grain size) and lower than the HPT-processed Zn ( 20 $\mu \mathrm{m}$ grain size $)$. However, when the hardness is measured at $90 \mathrm{~K}$, the HPT-processed Al-Zn alloy has a hardness much higher than the HPT-processed Al and $\mathrm{Zn}$. Therefore, the lower hardness of the ultrafine-grained Al-Zn alloy when compared to the hardness levels of pure $\mathrm{Al}$ and $\mathrm{Zn}$, as shown in Fig. 2(b), also should be due to a low melting temperature of the system. According to the XRD analysis in Fig. 4 and the elemental analysis in Figs. 6, it is apparent that elemental decomposition occurs during the HPT processing at room temperature, as expected from the equilibrium phase diagram [58]. However, a question arises if it is 
feasible for the decomposition to proceed within several minutes of HPT operation at ambient temperature. It is most conceivable that atomic diffusion must be accelerated by the HPT processing because of the generation of high-density lattice defects as reported in other papers [73-76]. In addition to the atomic diffusion, dynamic recovery and dynamic recrystallization also can affect the elemental decomposition. However, since these phenomena are dominant phenomena at the steady state and the elemental decomposition is completed at the onset of the steady state, the effect of these two phenomena on the decomposition can be reasonably neglected. The atomic diffusion may be influenced by the three factors during HPT operation: temperature, pressure and strain.

Temperature may rise during HPT processing because of plastic deformation, and enhance the atomic diffusion through the following Arrhenius-type equation [77]

$$
D=D_{0} \exp \left(-\frac{Q+P V_{F}}{R T}\right)
$$

where $D_{0}$ is the frequency factor, $Q$ is the activation energy for diffusion, $P$ is the applied pressure, $V_{F}$ is the activation volume, $R$ is the gas constant and $T$ is the absolute temperature. However, earlier studies showed that the temperature rise during HPT is not very significant when compared to the melting temperature of material, especially for the materials with low hardnesses [59,78]. Since the hardness of the present alloy is less than $200 \mathrm{Hv}$, the temperature of the sample during HPT processing should not exceed $330 \mathrm{~K}$, as discussed in details in Refs. [59,78]. When $Q=105.7 \mathrm{~kJ} / \mathrm{mol}[77], D_{0}=2.88 \times 10^{-5} \mathrm{~m}^{2} \mathrm{~s}^{-1}[77]$ and $P=0$ are used in Eq. (2), the temperature rise from $300 \mathrm{~K}$ to $330 \mathrm{~K}$ during HPT processing leads to an increase by $\sim 50$ times larger for the diffusion coefficient of the solute atoms of $\mathrm{Zn}$ in the AlZn alloy.

Meanwhile, the high pressure during HPT processing increases the energy barrier for atomic movements and suppresses the atomic diffusion [77,79], as given in Eq. (2). When $Q$ $=105.7 \mathrm{~kJ} / \mathrm{mol}[77], D_{0}=2.88 \times 10^{-5} \mathrm{~m}^{2} \mathrm{~s}^{-1}[77]$ and $V_{F}(\mathrm{Zn})=3.16 \times 10^{-6} \mathrm{~m}^{3} / \mathrm{mol}[79]\left(V_{F}(\mathrm{Zn})\right.$ 
was estimated $8.3-8.6 \times 10^{-6} \mathrm{~m}^{3} / \mathrm{mol}$ in Ref. [80] and 2.6-4.7 $\times 10^{-6} \mathrm{~m}^{3} / \mathrm{mol}$ in Ref. [81]) are input in Eq. (2) together with the operating pressure and temperature as $P=6 \mathrm{GPa}$ and $T=$ $300 \mathrm{~K}$, it follows that the diffusion coefficient is reduced by $\sim 0.0005$ times. Therefore, the pressure application is more dominant than the temperature rise so that the overall effect of both pressure and temperature appears to be minimal in the present HPT operation.

Strain imposed by HPT processing is intense and thus it is accompanied by a high density of lattice defects such as vacancies $[82,83]$, dislocations $[14,16]$ and grain boundaries [17-20]. The large fraction of the lattice defects then significantly reduces the activation energy for diffusion ( $Q$ in Eq. (2)) because of active contribution of short-circuit diffusion as well as a significant increase in vacancy population. Related evidences for the reduction of $Q$ were reported earlier with SPD-processed materials, especially at low temperatures [73-76].

The relation between the diffusion distance, $x$, and diffusion coefficient, $D$, is generally described for a given period of time, $t$, as [77]

$$
x=\sqrt{D t}
$$

Estimation of $D$ now results in $6 \times 10^{-17} \mathrm{~m}^{2} \mathrm{~s}^{-1}$ when $x$ is approximated to be the steady-state grain size, $x=\sim 190 \mathrm{~nm}$, and $t$ is the time to reach the steady state, $t=600 \mathrm{~s}$. Figure 11 plots the diffusion coefficients obtained using Eq. (3) for the HPT-processed Al-Zn and compares with those calculated using different magnitudes of $Q$ through Eq. (2), as attempted in an earlier paper [76], where $Q_{L}$ is the activation energy for lattice diffusion, $1 / 2-2 / 3$ of $Q_{L}$ is considered as the activation energy for dislocation-core and grain boundary diffusions, and $1 / 4-1 / 3$ of $Q_{L}$ is as the activation energy for surface diffusion. The values of $D_{0}$ and $Q_{L}$ were taken from Ref. [76] and they represent those for the solute diffusion coefficient. It is shown that the diffusion coefficient in this study increases by $10^{8}$ times when compared to the lattice diffusion and is well comparable with those for dislocation-core and grain boundary 
diffusions. It is then concluded that both elemental decomposition during HPT processing is accelerated by rapid diffusion mainly due to the presence of high density of lattice defects.

\section{Conclusions}

In this study, the influence of high-pressure torsion (HPT) processing and post-HPT annealing on the microstructure evolution and mechanical properties of an Al-Zn supersaturated alloy was investigated. The conclusions drawn from the results are summarized as follows.

1. A spinodal decomposition and the formation of a nano-sized lamellar structure occur in the solution-treated sample, but the lamellar structure is destroyed by HPT processing. The spinodal decomposition reoccurs in the HPT-processed samples after the subsequent annealing.

2. The HPT processing leads to elemental decomposition of the supersaturated alloy. Precipitates of $\mathrm{Zn}$ are also formed within the Al-rich grains after the HPT processing, while their fraction significantly decreases after the annealing.

3. During the HPT processing, the grain size decreases with straining and reaches a size of $\sim 190 \mathrm{~nm}$ at the steady-state, whereas the hardness decreases from $182 \mathrm{Hv}$ to a steadystate level of $28 \mathrm{Hv}$ by the HPT processing. The hardness increases after subsequent annealing despite the increase in the grain size.

4. Tensile strength decreases and ductility increases by imposing intense strain through the HPT processing, while both tensile strength and ductility improves by subsequent annealing at $373 \mathrm{~K}$.

5. The softening by HPT is less significant when the hardness is evaluated at low homologous temperatures. 
6. The transformation from nano-sized spinodal structure to equiaxed submicrometer grains is the main reason for the softening by HPT. The hardening by subsequent annealing is due to the spinodal decomposition for the formation of nano-sized lamellae.

7. The elemental decomposition during HPT processing occurs by rapid diffusion due to the presence of a high density of lattice defects. The diffusion coefficient estimated from the elemental decomposition during HPT processing appears to be $\sim 10^{8}$ times higher than the lattice diffusion and be comparable to grain boundary diffusion.

\section{Acknowledgements}

One of the authors (AA) would like to thank Indonesian Government for a Ph.D. scholarship through the Directorate of Higher Education Program (DGHE). One of the authors (KE) thanks the Japan Society for Promotion of Science (JSPS) for a Grant-in-Aid for Research Activity (No. 25889043). This work was supported in part by Japan Science and Technology Agency (JST) under Collaborative Research Based on Industrial Demand "Heterogeneous Structure Control: Towards Innovative Development of Metallic Structural Materials", in part by the Light Metals Educational Foundation of Japan, and in part by a Grant-in-Aid for Scientific Research from the MEXT, Japan, in Innovative Areas "Bulk Nanostructured Metals" (No. 22102004).

\section{Appendix}

The Fleischer's model for solid solution hardening is given as [56]:

$$
\Delta \tau=\frac{G\left|\varepsilon_{G}^{\prime}-m \varepsilon_{b}\right|^{3 / 2} c^{1 / 2}}{\alpha}
$$

The Labusch's model, which is appropriate for a large fraction of solute atoms, is given as [57]: 
$\Delta \tau=\frac{G\left[\varepsilon_{G}^{\prime}{ }^{2}+\left(15 \varepsilon_{b}\right)^{2}\right]^{2 / 3} c^{2 / 3}}{\varphi}$

In these equations, $\Delta \tau$ is the shear stress required for dislocation movement, $G$ is the shear modulus, $c$ is the concentration of solute atoms, $m=3$ for screw dislocations, $\alpha=700$ for fcc alloys, $\varphi=550$ for fcc alloys, $\varepsilon_{b}=(\mathrm{d} b / \mathrm{d} c) / b$ is the atomic size mismatch ( $b$ : Burgers vector) and $\varepsilon_{G}^{\prime}$ is the modulus mismatch parameter given as:

$\varepsilon_{G}^{\prime}=\frac{\varepsilon_{G}}{1+0.5 \varepsilon_{G}}$

where $\varepsilon_{G}=(\mathrm{d} G / \mathrm{d} c) / G$ is the modulus mismatch. If the value of $\varepsilon_{b}$ is estimated -0.02058 by fitting the data given in Ref. [58], $\varepsilon_{G}^{\prime}$ is estimated 0.46109 by employing the rule of mixtures for the Al-Zn alloys ( $G=26.2 \mathrm{GPa}$ for $\mathrm{Al}$ and $G=41.9 \mathrm{GPa}$ for $\mathrm{Zn}[18])$, shear stress is converted to normal stress using a Taylor factor of $\sim 3$ and the hardness is considered $\sim 3$ times higher than the normal stress, the contribution of solid solution hardening using the Fleischer's model and the Lubasch's model can be calculated for the Al-Zn alloys. Figure A1 plots the solid solution hardening effect calculated using the two models as a function of the $\mathrm{Zn}$ content in the Al matrix, indicating that the effect of solid solution hardening is less than $18 \mathrm{Hv}$. These calculated values are by one order of magnitude smaller than the hardness of solution-treated sample in this study $(182 \mathrm{Hv})$.

\section{References}

[1] V.M. Segal, V.I. Reznikov, A.E. Drobyshevskiy, V.I. Kopylov, Russian Metall. 1 (1981) 99-105.

[2] M. Furukawa, Y. Ma, Z. Horita, M. Nemoto, R.Z. Valiev, T.G. Langdon, Mater. Sci. Eng. A 241 (1998) 122-128.

[3] M. Furukawa, Z. Horita, M. Nemoto, T.G. Langdon, J. Mater. Sci. 36 (2001) 28352843. 
[4] S.C. Baik, Y. Estrin, H.S. Kim, R.J. Hellmig, Mater. Sci. Eng. A 351 (2003) 86-97.

[5] G. Purcek, B.S. Altan, I. Miskioglu, P.H. Ooi, J. Mater. Proc. Technol. 148 (2004) 279287.

[6] R.Z. Valiev, T.G. Langdon, Prog. Mater. Sci. 51 (2006) 881-981.

[7] Y. Saito, H. Utsunomiya, N. Tsuji, T. Sakai, Acta Mater. 47 (1999) 579-583.

[8] M.Y. Zhan, Y.Y. Li, W.P. Chen, W.D. Chen, J. Mater. Sci. 42 (2007) 9256-9261.

[9] P.W. Bridgman, Phys. Rev. 48 (1935) 825-847.

[10] A.P. Zhilyaev, G.V. Nurislamova , B.K. Kim, M.D. Baro, J.A. Szpunar, T.G. Langdon, Acta Mater. 51 (2003) 753-765.

[11] G. Sakai, Z. Horita, T.G. Langdon, Mater. Sci. Eng. A 393 (2005) 344-351.

[12] X.Z. Liao, A.R. Kilmametov, R.Z. Valiev, H. Gao, X. Li, A.K. Mukherjee, J.F. Bingert, Y.T. Zhu, Appl. Phys. Lett. 88 (2006) 021909.

[13] R. Pippan, S. Scheriau, A. Taylor, M. Hafok, A. Hohenwarter, A. Bachmaier, Annu. Rev. Mater. Res. 40 (2010) 319-343.

[14] J. Zhang, N. Gao, M.J. Starink, Mater. Sci. Eng. A 527 (2010) 3472-3479.

[15] F.A. Mohamed, S.S. Dheda, Mater. Sci. Eng. A 558 (2012) 59-63.

[16] M.J. Starink, X. Cheng, S. Yang, Acta Mater. 61 (2013) 183-192.

[17] A.P. Zhilyaev, T.G. Langdon, Prog. Mater. Sci. 53 (2008) 893-979.

[18] K. Edalati, Z. Horita, Acta Mater. 59 (2011) 6831-6836.

[19] R.Z. Valiev, R.K. Islamgaliev, I.V. Alexandrov, Prog. Mater. Sci. 45 (2000) 103-189.

[20] R.Z. Valiev, Y. Estrin, Z. Horita, T.G. Langdon, M.J. Zehetbauer, Y.T. Zhu, JOM. 58(4) (2006) 33-39.

[21] A. Azushima, R. Kopp, A. Korhonen, D.Y. Yang, F. Micari, G.D. Lahoti, P. Groche, J. Yanagimoto, N. Tsuji, A. Rosochowski, A. Yanagida, CIRP Annals-Manuf. Technol. 57 (2008) 716-735. 
[22] B.B. Straumal, A.A. Mazilkin, B. Baretzky, G. Schutz, E. Rabkin, R.Z. Valeiv, Mater. Trans. Vol. 53 (2012) 63-71.

[23] N.A. Koneva, E.V. Kozlov, Y.F. Ivanov, N.A. Popova, A.N. Zhdanov, Mater. Sci. Eng. A 410-411 (2005) 341-344.

[24] Y. Todaka, J. Sasaki, T. Moto, M. Umemoto, Scripta Mater. 59 (2008) 615-618.

[25] B. Srinivasarao, A.P. Zhilyaev, M.T. Perez-Prado, Scripta Mater. 65 (2011) 241-244.

[26] Y. Ikoma, K. Hayano, K. Edalati, K. Saito, Q. Guo, Z. Horita, Appl. Phys. Lett. 101 (2012) 121908.

[27] K. Edalati, T. Daio, Y. Ikoma, M. Arita, Z. Horita, Appl. Phys. Lett. 103 (2013) 034108.

[28] K. Edalati, S. Toh, Y. Ikoma, Z. Horita, Scripta Mater. 65 (2011) 974-977.

[29] K. Edalati, Z. Horita, Mater. Sci. Eng. A 528 (2011) 7514-7523.

[30] K. Edalati, A. Yamamoto, Z. Horita, T. Ishihara, Scripta Mater. 64 (2011) 880-883.

[31] C. Xu, Z. Horita, T.G. Langdon, Acta Mater. 55 (2007) 203-212.

[32] Y. Harai, Y. Ito, Z. Horita, Scripta Mater. 58 (2008) 469-482.

[33] Y. Ito, Z. Horita, Mater. Sci. Eng. A 503 (2009) 32-36.

[34] M. Kawasaki, R.B. Figueiredo, T.G. Langdon, Acta Mater. 59 (2011) 308-316.

[35] K. Edalati, Y. Ito, K. Suehiro and Z. Horita, Inter. J. Mater. Res., 100 (2009) 16681673.

[36] Y. Huang, R.B. Figueiredo, T. Baudin, F. Brisset, T.G. Langdon, Adv. Eng. Mater. 14 (2012) 1018-1026.

[37] Y. Huang, R.B. Figueiredo, T. Baudin, F. Brisset, T.G. Langdon, J. Mater. Sci. 47 (2012) 7796-7806.

[38] B. Srinivasarao, A.P. Zhilyaev, T.G. Langdon, M.T. Perez-Prado, Mater. Sci. Eng. A 562 (2013) 196-202.

[39] M. Kawasaki, B. Ahn, T.G. Langdon, Acta Mater. 58 (2010) 919-930. 
[40] M. Kawasaki, B. Ahn, T.G. Langdon, Mater. Sci. Eng. A 527 (2010) 7008-7016.

[41] N.X. Zhang, M. Kawasaki, Y. Huang, T.G. Langdon, J. Mater. Sci. 48 (2013) 45824591.

[42] C.F. Yang, J.H. Pan, T.H. Lee, J. Alloys Compd. 468 (2009) 230-236.

[43] B.B. Straumal, B. Baretzky, A.A. Mazilkin, F. Phillipp, O.A. Kogtenkova, M.N. Volkov, R.Z. Valiev, Acta Mater. 52 (2004) 4469-4478.

[44] A.A. Mazilkin, B.B. Straumal, E. Rabkin, B. Baretzky, S. Enders, S.G. Protasova, O.A. Kogtenkova, R.Z. Valiev, Acta Mater. 54 (2006) 3933-3939.

[45] A.A. Mazilkin, B. Baretzky, S. Enders, O.A. Kogtenkova, B.B. Straumal, E. Rabkin, R.Z. Valiev, Def. Diff. Forum 249 (2006) 155-160.

[46] R.Z. Valiev, M.Y. Murashkin, A. Kilmametov, B.B. Straumal, N.Q. Chinh, T.G. Langdon, J. Mater. Sci. 45 (2010) 4718-4724.

[47] A.A. Mazilkin, B.B. Straumal, M.V. Borodachenkova, R.Z. Valiev, O.A. Kogtenkova, B. Baretzky, Mater. Lett. 84 (2012) 63-65.

[48] N.Q. Chinh, T. Csandi, T. Gyori, R.Z. Valiev, B.B. Straumal, M. Kawasaki, T.G. Langdon, Mater. Sci. Eng. A 543 (2012) 117-120.

[49] B.B. Straumal, X. Sauvage, B. Baretzky, A.A. Mazilkin, R.Z. Valiev, Scripta Mater. 70 (2014) 59-62.

[50] N.Q. Chinh, R.Z. Valiev, X. Sauvage, G. Varga, K. Havancsak, M. Kawasaki, B.B. Straumal, T.G. Langdon, Adv. Eng. Mater. 2014; in press.

[51] M. Borodachenkova, F. Barlat, W. Wen, A. Bastos, J.J. Gracio, Int. J. Plasticity 2014; in press.

[52] C.F. Yang, J.H. Pan, T.H. Lee, J. Alloys. Compd. 468 (2009) 230-236.

[53] M. Tavoosi, M.H. Enayati, F. Karimzadeh, J. Alloys Compd. 464 (2008) 107-110.

[54] O. Saray, G. Purcek, J. Mater. Proc. Technol. 209 (2009) 2488-2498. 
[55] G. Purcek, O. Saray, I. Karaman, T. Kucukomeroglu, Mater. Sci. Eng. A 490 (2008) 403-410.

[56] R.L. Fleischer, Acta Metall. 11 (1963) 203-209.

[57] R. Labusch, Acta Metall. 20 (1972) 917-927.

[58] J.L. Murray, Bull. Alloy Phase Diagrams 4 (1983) 55-73.

[59] K. Edalati, R. Miresmaeili, Z. Horita, H. Kanayama, R. Pippan, Mater. Sci. Eng. A 528 (2011) 7301-7305.

[60] D.L. Douglass, T.W. Barbee, J. Mater. Sci. 4 (1969) 121-129.

[61] R. Acuna, A. Bonfiglioli, Acta Metall. 22 (1974) 399-408.

[62] M. Vijayalakshmi, V. Seetharaman, V.S. Raghunathan, J. Mater. Sci. 17 (1982) 126134.

[63] S. Komura, K. Osamura, H. Fuji, T. Takeda, Physica 120B (1983) 397-400.

[64] R. Ramlau, H. Loffler, Acta Metall. 35 (1987) 2005-2014.

[65] W.J. Kim, J.K. Park, Acta Metall. Mater. 41 (1993) 441-449.

[66] P. Zieba, A. Pawlowski, Mater. Sci. Eng. A 187 (1994) 57-63.

[67] Y. Zhang, X. Zeng, L. Yang, K. Sun, Z. Song, Phil. Mag. Lett. 93 (2013) 322-330.

[68] I. Yonenaga, T. Suzuki, Philos. Mag. Lett. 82 (2002) 535-542.

[69] X. Huang, N. Hansen, N. Tsuji, Science, 312 (2006) 249-251.

[70] J.W. Cahn, Acta Metall. 9 (1961) 795-801.

[71] H.J. Frost, M. F. Ashby, Deformation-mechanism maps: The plasticity and creep of metals and ceramics, Pergamon Press, Oxford, 1982.

[72] K. Edalati, Z. Horita, Rev. Adv. Mater. Sci. 31 (2012) 5-11.

[73] T. Fujita, Z. Horita, T.G. Langdon, Mater. Sci. Eng. A 371 (2004) 241-250.

[74] X. Sauvage, Mater. Sci. Forum 503-504 (2006) 433-438.

[75] S.V. Divinski, J. Ribbe, D. Baither, G. Schmitz, G. Reglitz, H. Rosner, K. Sato, Y. Estrin, G. Wilde, Acta Mater. 57 (2009) 5706-5717. 
[76] K. Oh-ishi, K. Edalati, H.S. Kim, K. Hono, Z. Horita, Acta Mater. 61 (2013) 34823489.

[77] H. Mehrer, Numerical Data and Functional Relationship in Science and Technology, Diffusion in Solid Metals and Alloys, vol. 26, Berlin, Springer; 1990.

[78] R.B. Figueiredo, P.H.R. Pereira, M.T.P. Aguilar, P.R. Cetlin, T.G. Langdon, Acta Mater. 60 (2012) 3190-3198.

[79] Y. Kraftmakher, Phys. Rep. 299 (1998) 79-188.

[80] K. Hisayuki, T. Yamane, T. Takahashi, Y. Minamino, K. Hirao, H. Araki, J. Mater. Sci. 34 (1999) 2449-2454.

[81] P. Klugkist, A.N. Aleshin, W. Lojkowski, L.S. Shvindlerman, W. Gust, E.J. Mittemeijer, Acta Mater. 49 (2001) 2941-2949.

[82] B. Oberdorfer, B. Lorenzoni, K. Unger, W. Sprengel, M. Zehetbauer, R. Pippan, R. Wurschum, Scripta Mater. 63 (2010) 452-455.

[83] D. Setman, E. Schafler, E. Korznikova, M.J. Zehetbauer, Mater. Sci. Eng. A 493 (2008) 116-122. 


\section{Table Captions}

Table 1. Melting point, processing technique, average grain size, Vickers microhardness at $300 \mathrm{~K}$ and Vickers microhardness at $90 \mathrm{~K}$ for pure $\mathrm{Al}$ (99.99\%), pure Zn (99.99\%) and $\mathrm{Al}$ - 30 mol.\% Zn alloy.

\section{Figure Captions}

Figure 1. (a) Optical micrograph and (b) TEM bright-field image and corresponding SAED pattern of sample after cold rolling and solution treatment at $673 \mathrm{~K}$ for $1 \mathrm{~h}$.

Figure 2. Vickers microhardness plotted against (a) distance from disc center and (b) shear strain for samples processed by HPT through $N=1,3,10$ and 25 revolutions, including steady-state levels for HPT-processed pure Al (99.99\%) and Zn $(99.99 \%)$.

Figure 3. Vickers microhardness plotted against (a) annealing temperature for samples annealed for $24 \mathrm{~h}$ and (b) annealing time for samples annealed at $373 \mathrm{~K}$ after HPT processing through $N=25$ revolutions.

Figure 4. XRD profiles for (a) samples processed by HPT through $N=1,3,10$ and 25 revolutions including solution-treated sample and (b) samples annealed at various temperatures for $24 \mathrm{~h}$ after HPT processing for $N=25$ revolutions.

Figure 5. TEM micrographs and corresponding SAED patterns for samples processed by HPT through (a, b) $N=1$ and (c, d) $N=10$ revolutions, where (a-c) are bright-field images and (d) is dark-field image of (c) taken with diffracted beams indicated by arrow in SAED pattern. 
Figure 6. (a, d) STEM bright-field images and corresponding EDS mappings with (b, e) Al and (c, f) $\mathrm{Zn}$ for samples processed by HPT through $N=25$ revolutions. Zn-rich precipitates were indicated by arrows.

Figure 7. TEM bright-field images for sample annealed for $24 \mathrm{~h}$ at (a) $373 \mathrm{~K}$, (b) $593 \mathrm{~K}$ and (c) $673 \mathrm{~K}$ after HPT processing through $N=25$ revolutions. Corresponding SAED pattern of samples annealed at $593 \mathrm{~K}$ and $673 \mathrm{~K}$ were included.

Figure 8. (a, c, e) STEM bright-field images and corresponding EDS mappings with (b, d) Al and (f) $\mathrm{Zn}$ for sample annealed at $373 \mathrm{~K}$ for $24 \mathrm{~h}$ after HPT processing through $N=$ 25 revolutions. Zn-rich precipitates were indicated by arrows.

Figure 9. (a) TEM high resolution image and FFT analyses of square regions indicated as (b) A and (c) B in high resolution image for sample annealed at $373 \mathrm{~K}$ for $24 \mathrm{~h}$ after HPT processing. A and $\mathbf{B}$ correspond to $\mathrm{Al}$ and $\mathrm{Zn}$, respectively.

Figure 10. Nominal stress versus nominal strain curves for samples processed by HPT through $N=1,3,10$ and 25 revolutions and sample annealed at $373 \mathrm{~K}$ for $1 \mathrm{~h}$ after HPT processing through $N=25$ including solution-treated sample. Inset for dimensions of tensile specimen.

Figure 11. Estimated diffusion coefficient during HPT processing plotted against $\mathrm{Zn}$ content in comparison with reference data [77] which were calculated using three different activation energies such as lattice diffusion $\left(Q=Q_{L}\right)$, grain boundary diffusion $(Q$ $\left.=(1 / 2-2 / 3) Q_{L}\right)$ and surface diffusion $\left(Q=(1 / 4-1 / 3) Q_{L}\right)$. 
Figure A1. Increase in hardness by solution hardening predicted by Fleischer's model and Labusch's model. 
Table 1

\begin{tabular}{llllll}
\hline Materials & $\begin{array}{l}\text { Melting } \\
\text { Point } \mathbf{( K )}\end{array}$ & Process & $\begin{array}{l}\text { Grain Size } \\
(\boldsymbol{\mu} \mathbf{m})\end{array}$ & $\begin{array}{l}\text { Hardness } \\
(\mathbf{H v}) \text { at 300 K }\end{array}$ & $\begin{array}{l}\text { Hardness } \\
(\mathbf{H v}) \text { at 90 K }\end{array}$ \\
\hline $\mathbf{A l}$ & 933 & Anneal & 1000 & 22 & 25 \\
$\mathbf{( 9 9 . 9 9 \% )}$ & 933 & HPT & 1.3 & 32 & 73 \\
$\mathbf{Z n}$ & 693 & Anneal & 390 & 37 & 72 \\
$\mathbf{( 9 9 . 9 9 \% )}$ & 693 & HPT & 20 & 33 & 86 \\
& 830 & Solution & $130+$ & 182 & 219 \\
$\mathbf{A l - Z n}$ & & Treatment & Nanolamellae & 28 & 199 \\
& 830 & HPT & 0.190 & 28 & \\
\hline
\end{tabular}



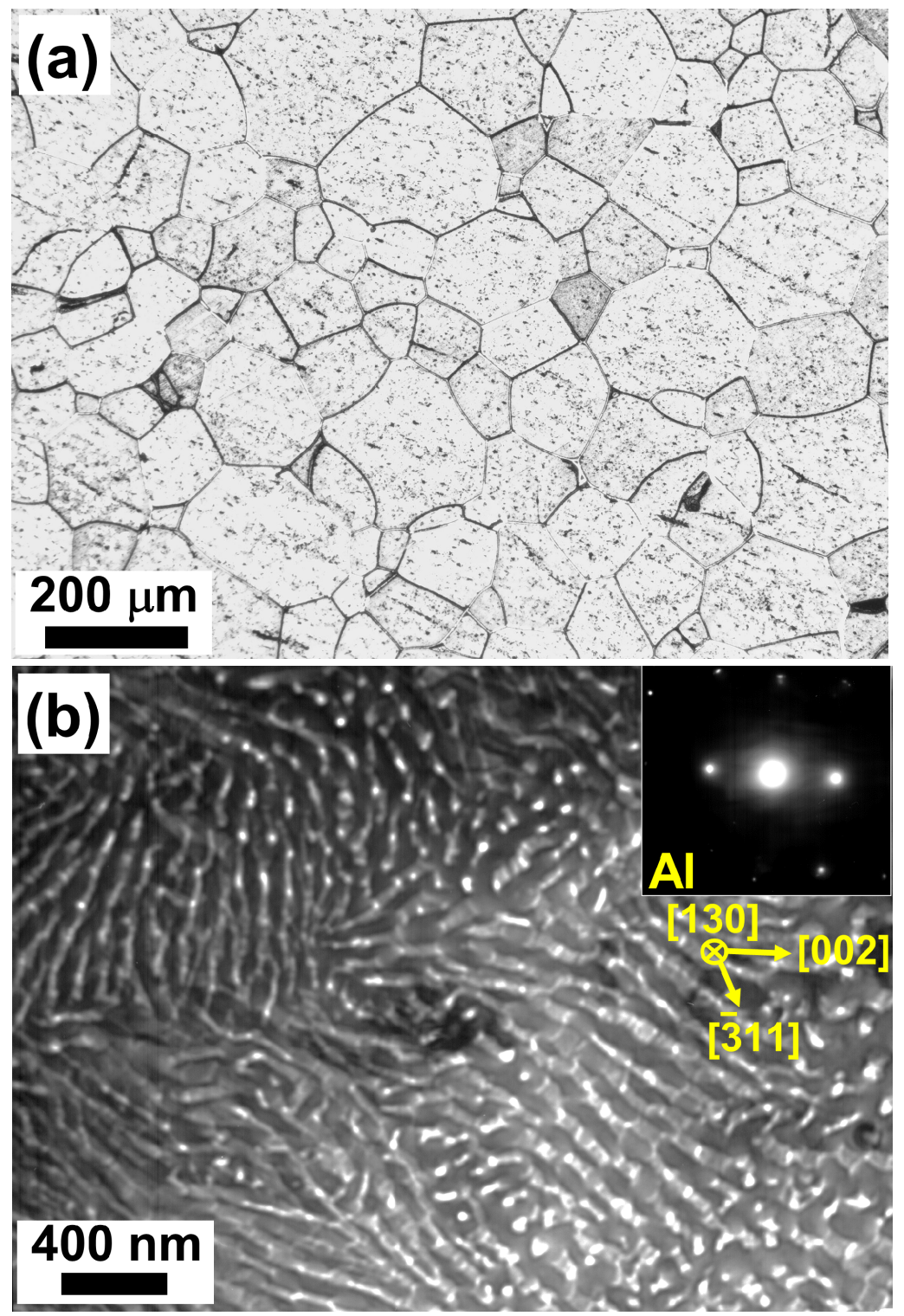

Figure 1 
(a)
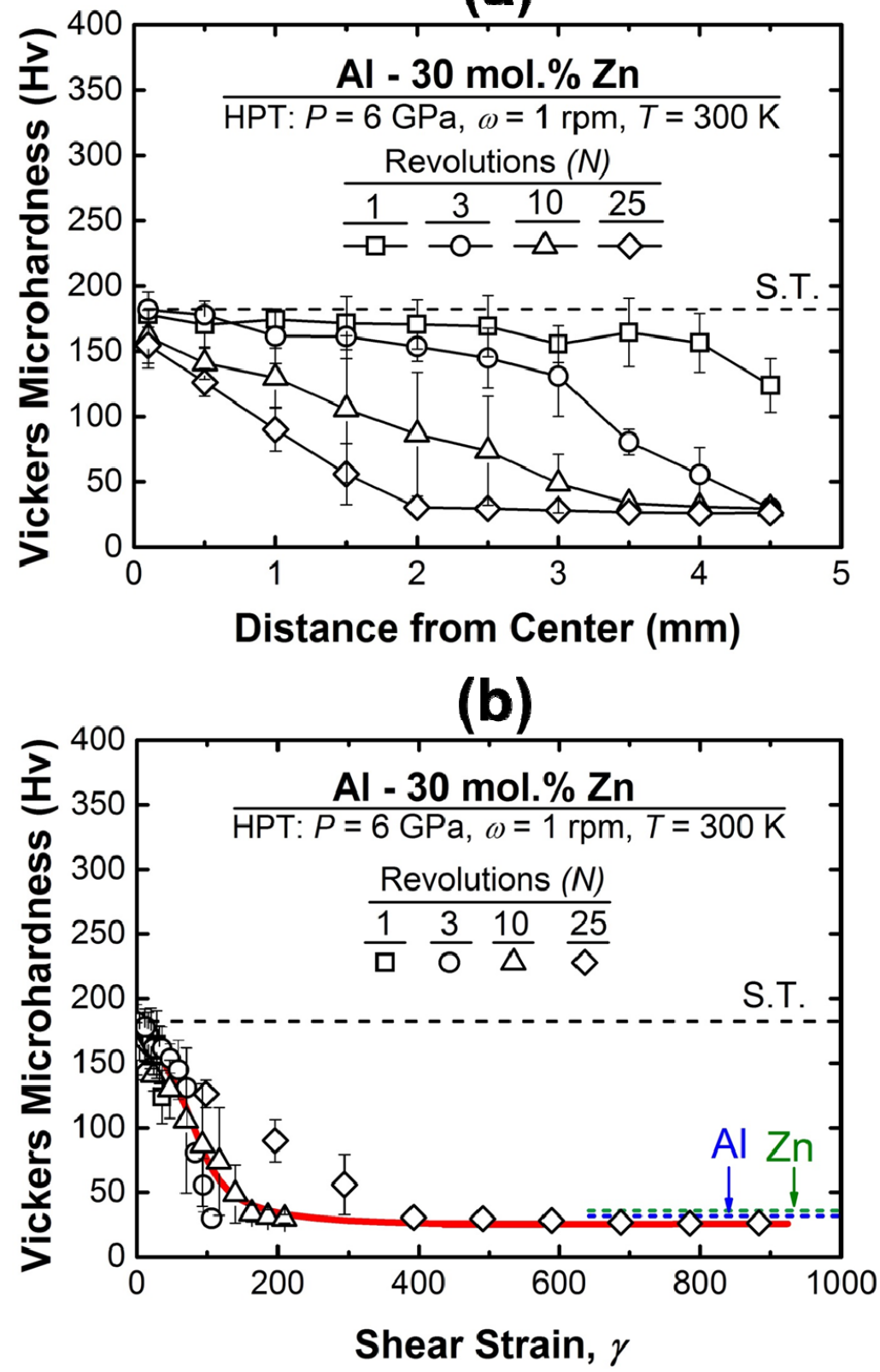

Figure 2 
(a)
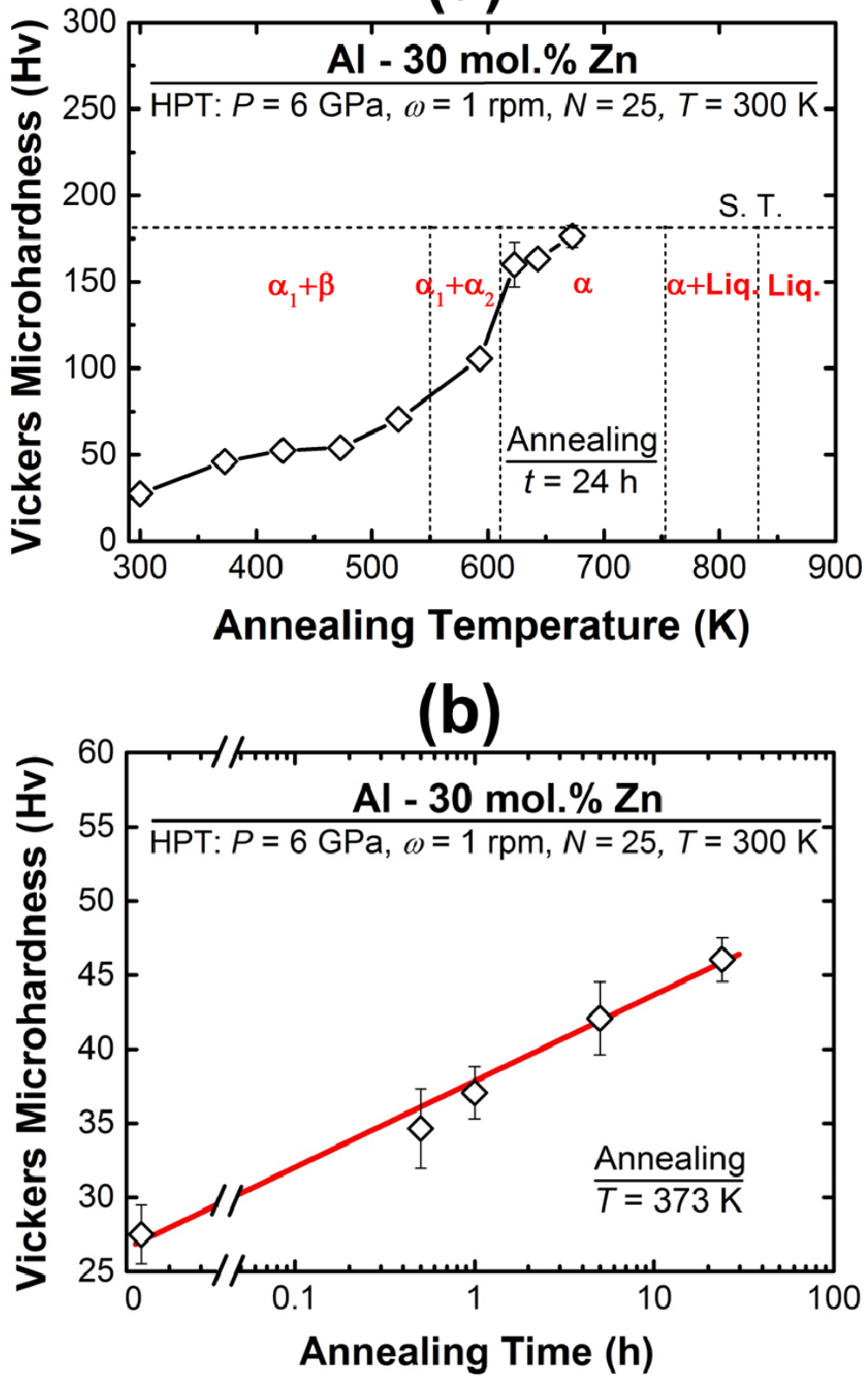

Figure 3 
(a)

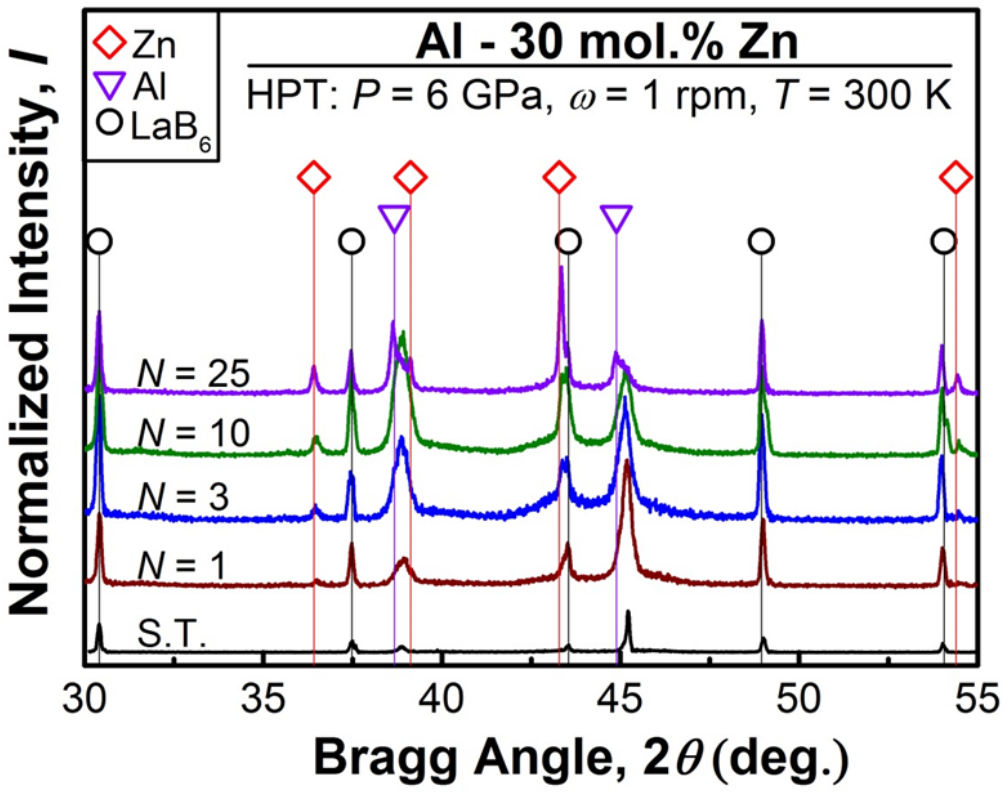

(b)

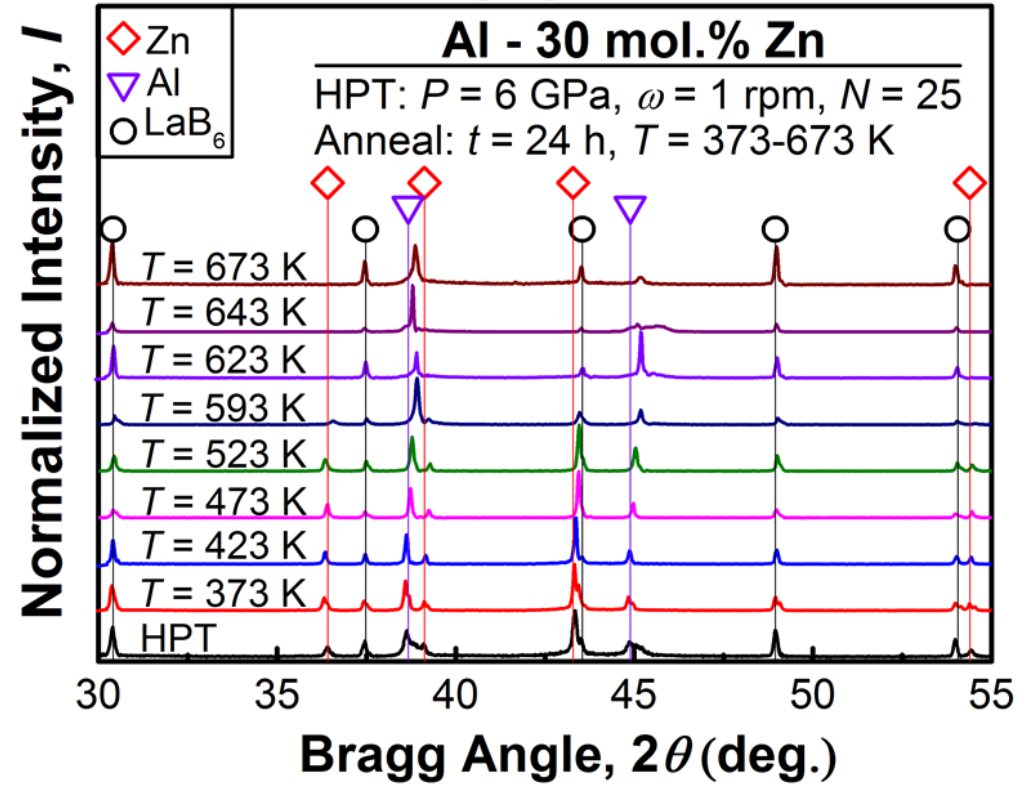

Figure 4 


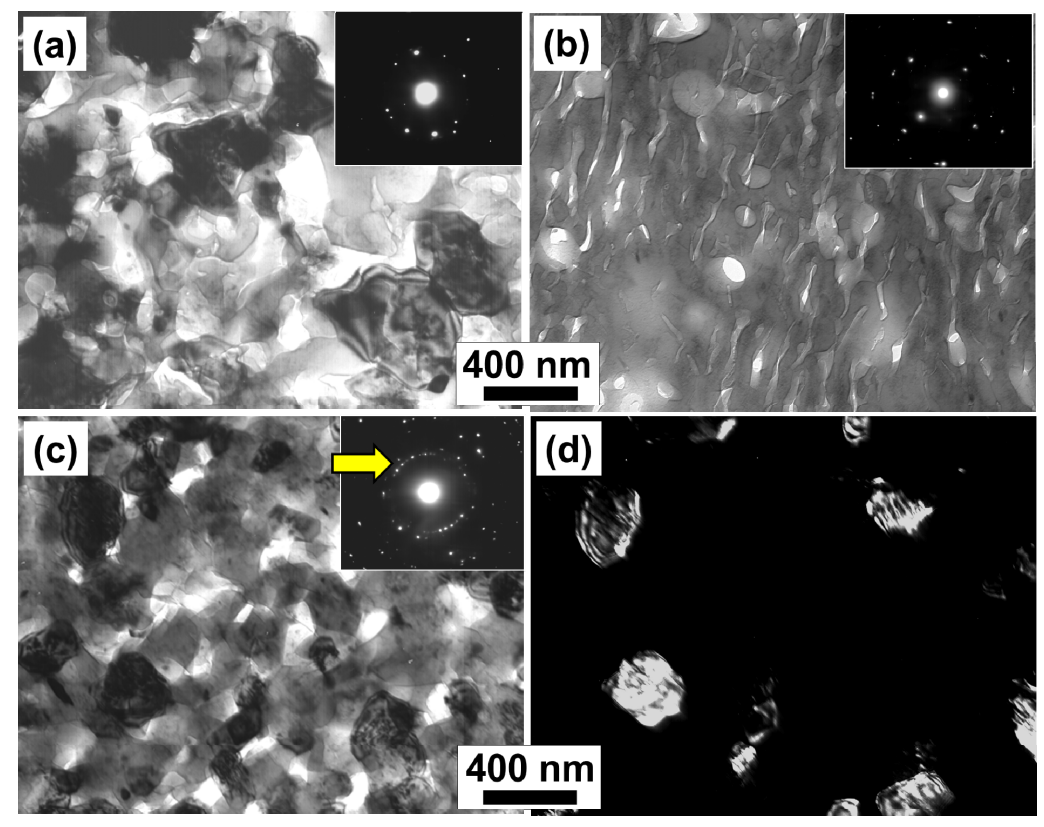

Figure 5 

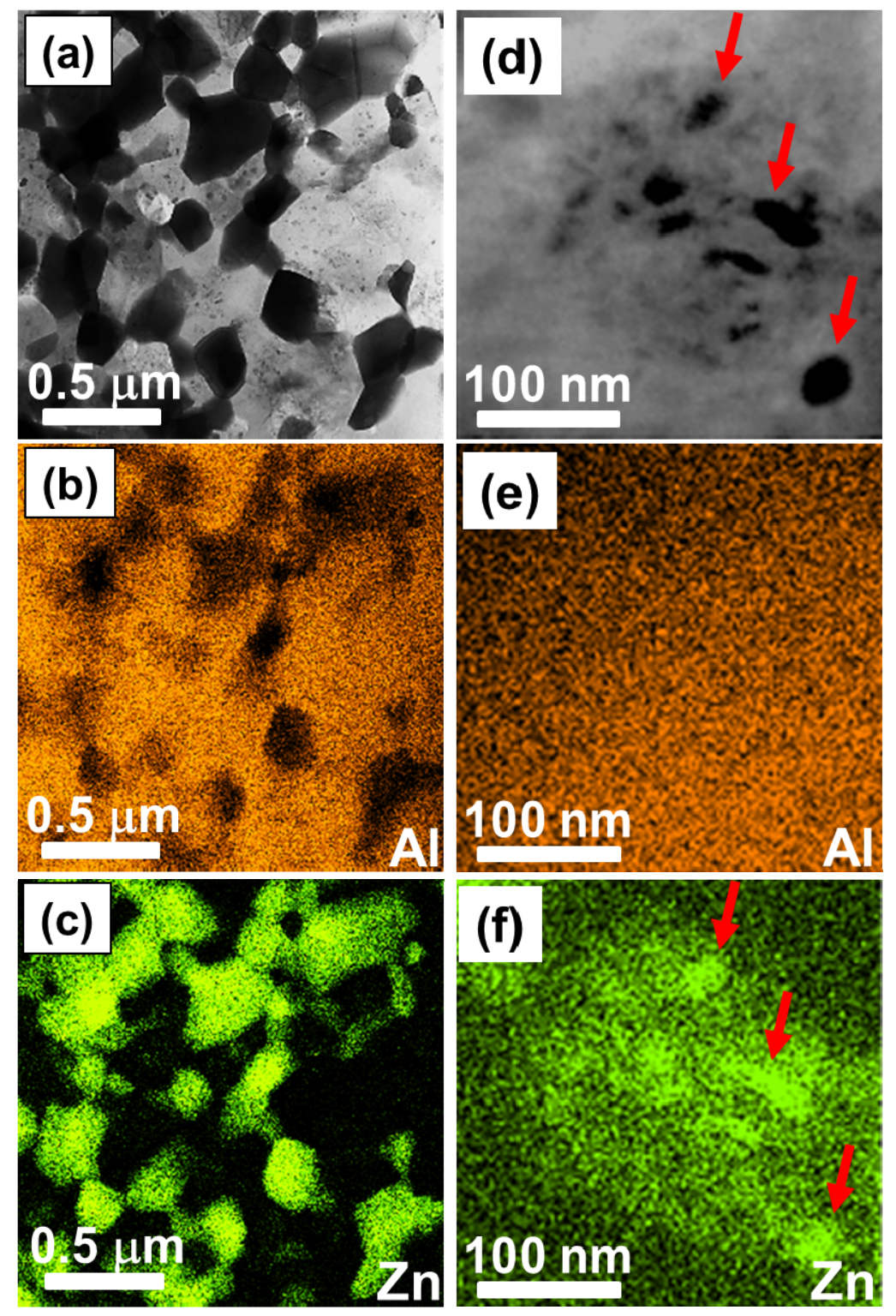

Figure 6 

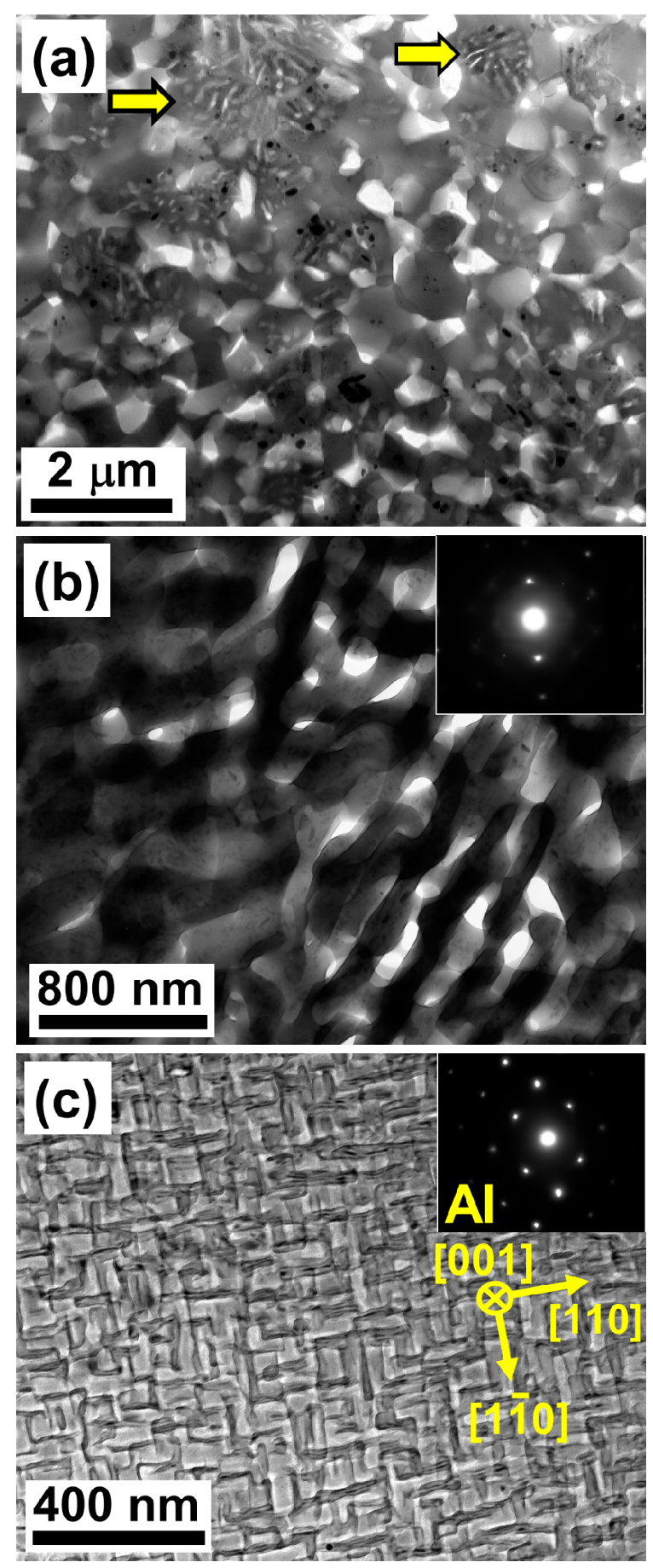

Figure 7 

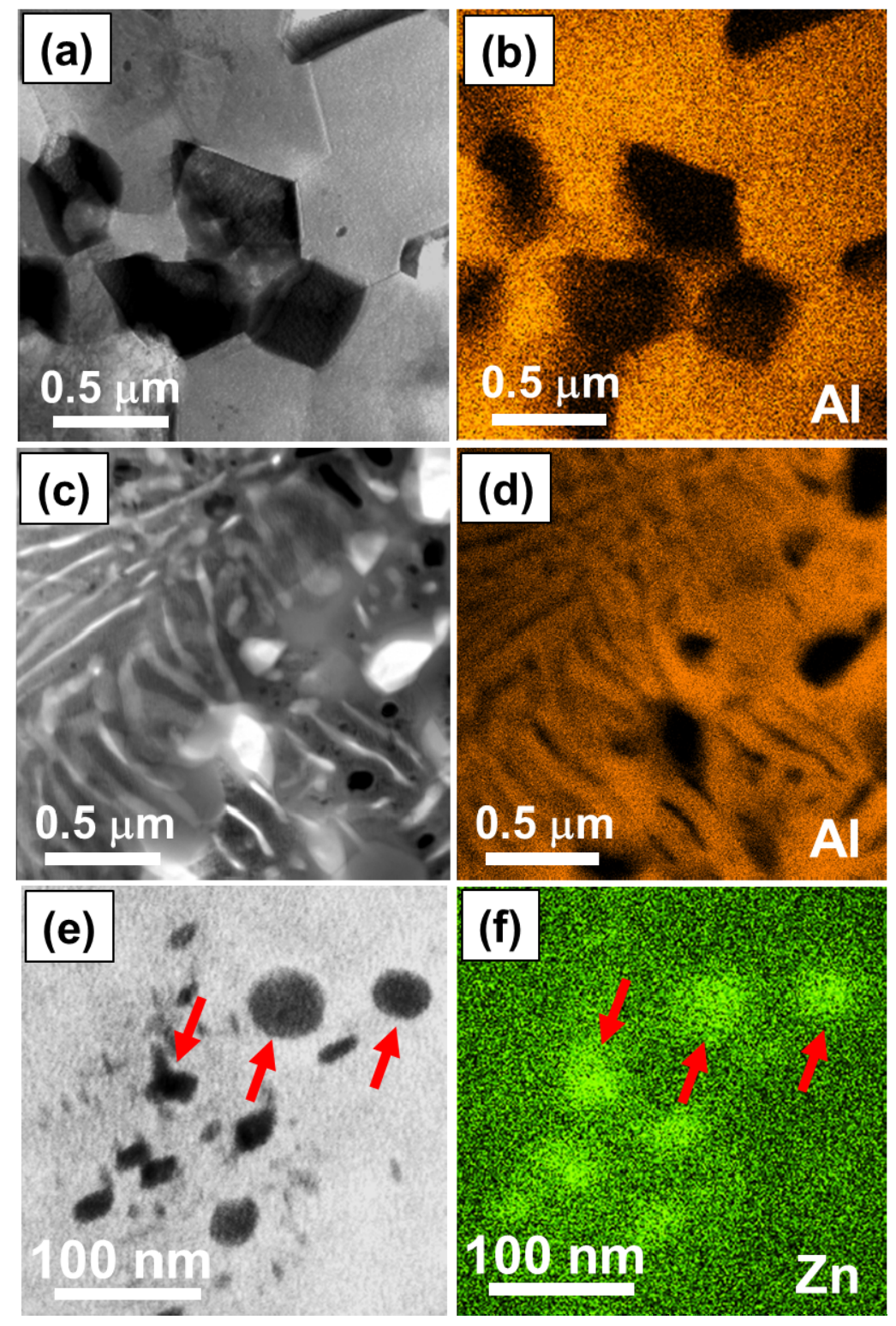

Figure 8 

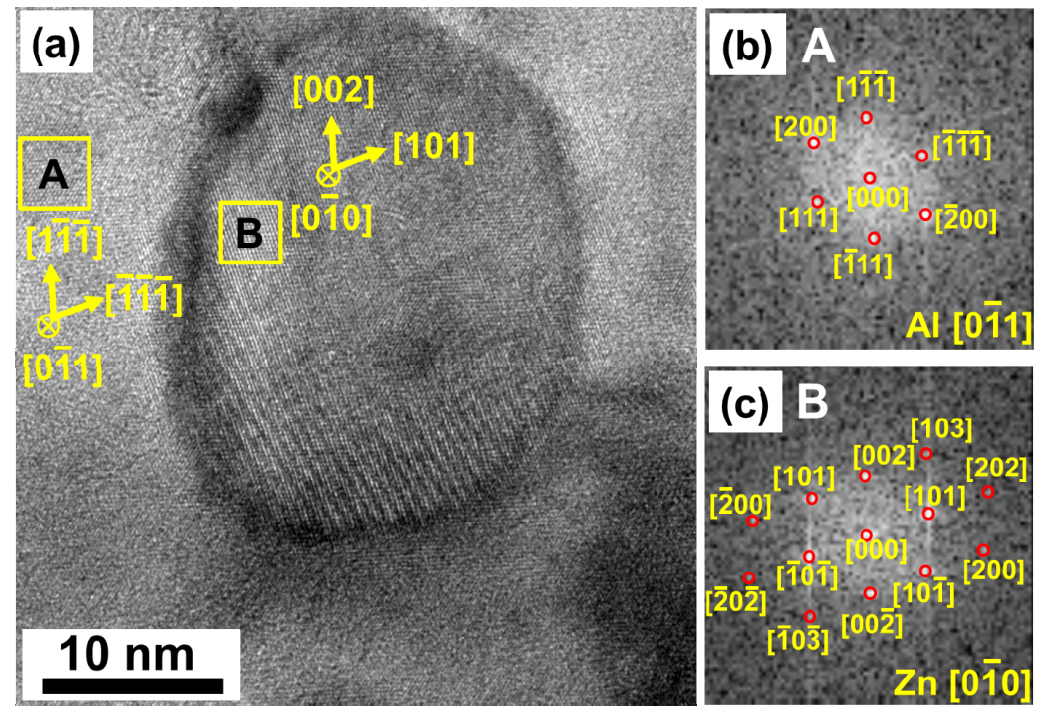

Figure 9 


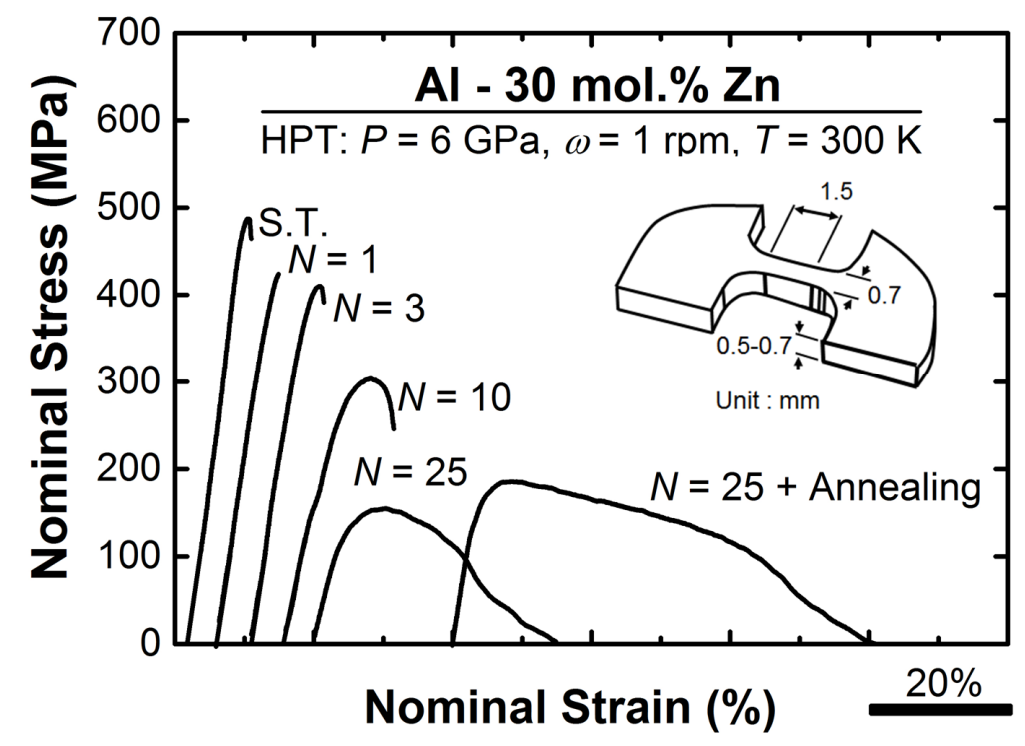

Figure 10 


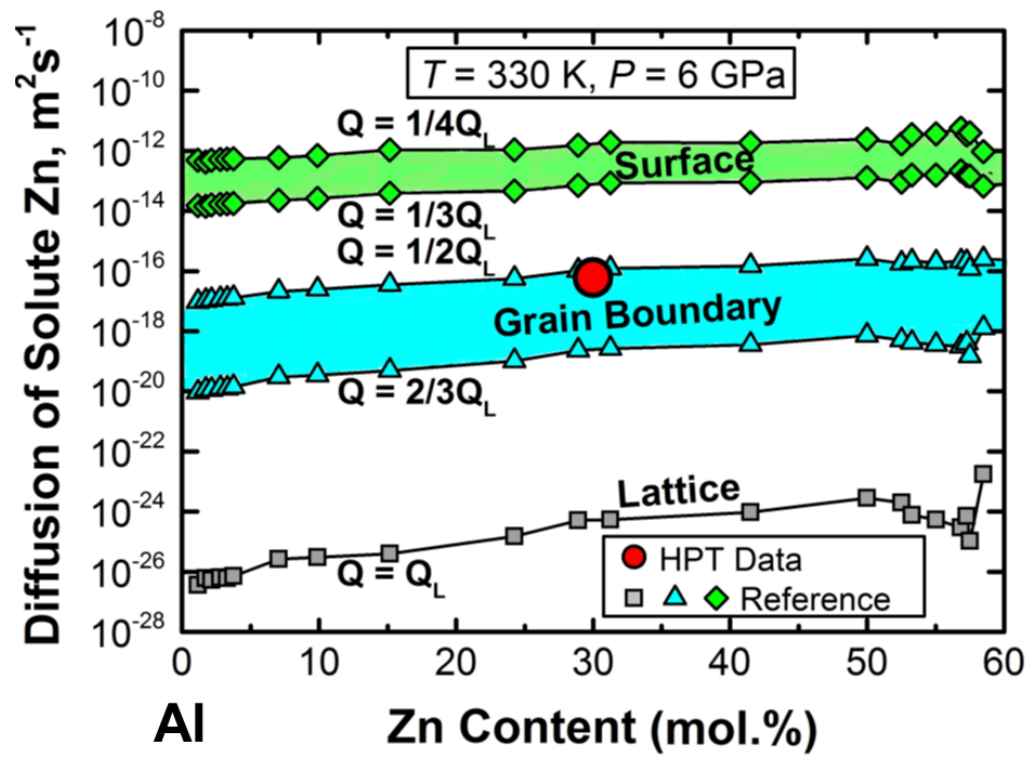

Figure 11 


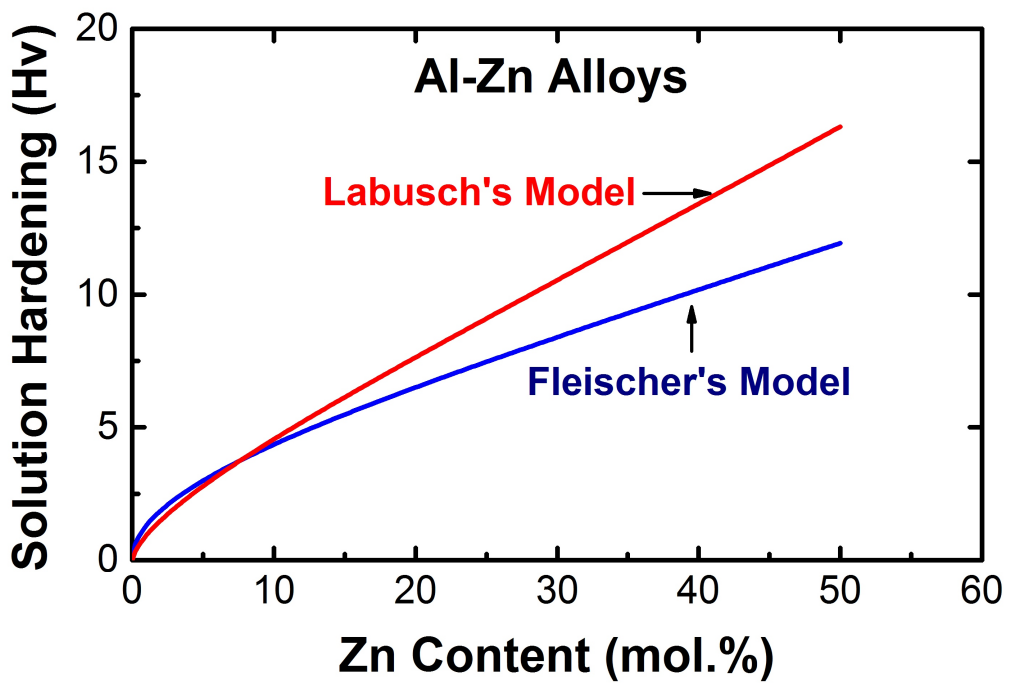

Figure A1 